\title{
Competitive Profiling of Ligandable Cysteines in Staphylococcus aureus with an Organogold Compound
}

\author{
Claudia Schmidt, ${ }^{a,+}$ Michael Zollo, ${ }^{b,+}$ Riccardo Bonsignore, ${ }^{a, c}$ Angela Casini ${ }^{a, *}$ and Stephan M. Hacker ${ }^{b, d, *}$ \\ ${ }^{a}$ Chair of Medicinal and Bioinorganic Chemistry, Department of Chemistry, Technical University of Munich, Lichtenbergstr. 4, 85748 Garching, Germany \\ ${ }^{b}$ Department of Chemistry, Technical University of Munich, Lichtenbergstr. 4, 85748 Garching, Germany. \\ 'Dipartimento di Scienze e Tecnologie Biologiche, Chimiche e Farmaceutiche, Università degli Studi di Palermo, Viale delle Scienze, Edificio 17, 90128 Palermo, Italy. \\ ${ }^{d}$ Leiden Institute of Chemistry, Leiden University, Einsteinweg 55, 2333 CC Leiden, The Netherlands. \\ † These authors contributed equally to this work. \\ * Corresponding authors: s.m.hacker@lic.leidenuniv.nl, angela.casini@tum.de
}

With the idea of exploiting metal-templated reactions to achieve selective modification of cysteines in proteins for antibacterial applications, an organometallic cyclometalated $\mathrm{Au}$ (III) compound was explored in a competitive chemoproteomic approach based on the isoDTB-ABPP (isotopically labelled desthiobiotin azide-activity-based protein profiling) technology in S. aureus cell extracts. In this way, more than 100 ligandable cysteines where identified, of which 10 were close to functional sites of proteins encoded by essential genes indicating potential for antibiotic development. Interestingly, more than $50 \%$ of the identified ligandable sites were not engaged by organic $\alpha$-chloroacetamides in a previous study, indicating that organometallic compounds expand the ligandable space in bacteria. A selected interaction identified by isoDTB-ABPP was validated using an enzyme activity assay, and intact protein mass spectrometry showed that cysteine arylation of an unprecedented target occurs with the studied compound. The obtained results constitute the proof-of-concept that this family of organogold compounds has potential for therapeutic protein targeting via selective, covalent modification of cysteine residues in bacteria. Looking more broadly, our study demonstrates that the targets of cyclometalated gold compounds can be studied proteome-wide with competitive residue-specific chemoproteomics enabling the expansion of the known ligandable proteome to sites that can be addressed with this compound class.

\section{Introduction}

Bacterial antimicrobial resistance is one of the leading causes of death world-wide and is estimated to have directly caused more than 1.2 million deaths in $2019 .{ }^{1}$ One way to overcome this global health challenge will be the identification of novel antibacterial targets that can be liganded with small molecules. ${ }^{2}$ While recent successes with reversible, organic compounds show that there is still a lot of potential to address new targets with known concepts, $^{3-6}$ systematically exploring other compound classes for antibacterial activity could open up entirely new target families. Using the isoDTB-ABPP (isotopically labelled desthiobiotin azide-activity-based protein profiling) technology, ${ }^{7}$ which is based on the isoTOP-ABPP (isotopic tandem orthogonal proteolysis-ABPP) platform, ${ }^{8,9}$ we have recently demonstrated that irreversible, cysteine-directed covalent inhibitors in combination with competitive, residue-specific chemoproteomic approaches allow efficient identification of many new binding sites with ligandable cysteines in bacteria in parallel. ${ }^{7}$

In this context, in recent years, it has become evident that metal complexes possess many attractive properties that make them good therapeutic candidates for addressing elusive target proteins especially for antibiotic applications. ${ }^{10-16}$ This is based on unique 3D structures that are inaccessible to organic molecules, but can be attained with metal-based compounds facilitating their binding to specific target sites, ${ }^{10,17}$ as well as by the ability of metal complexes to undergo activation by redox process and ligand exchange reactions in cells. ${ }^{18,}{ }^{19}$ Notably, organometallic compounds featuring a direct metalcarbon bond have attracted increasing attention as therapeutic agents, since they promote previously unattainable chemical transformations in biological environment, ${ }^{20,} 21$ including cross-coupling reactions, ${ }^{22-24}$ cycloadditions, ${ }^{25}$ hydrogenation and transfer hydrogenation reactions, ${ }^{26}, 27$ ester amidation ${ }^{28}$ or functional group deprotection (uncaging) reactions ${ }^{29}$.

Recently, some of us started working on organometallic $\mathrm{Au}(\mathrm{III})$ complexes of different families, which were shown to possess anticancer and antibacterial properties. ${ }^{30-35}$ Specifically, we focused on cyclometalated $\mathrm{Au}$ (III) $\mathrm{C}^{\wedge} \mathrm{N}$ complexes and on the identification of their protein targets and respective binding modes. ${ }^{18,35,36}$ It was observed that organogold compounds in this family can template the formation of covalent $\mathrm{C}^{\wedge} \mathrm{N}$-peptide adducts via $\mathrm{C}-\mathrm{S}$ cross-coupling at cysteine residues. ${ }^{37-39}$ Among the selected $\mathrm{Au}(\mathrm{III})$ complexes, the $\left[\mathrm{Au}\left(\mathrm{CCON}^{\mathrm{CO}} \mathrm{Cl}_{2}\right]\right.$ compound (1, C CON = 2-benzoylpyridine, Fig. 1a) was identified as the most reactive and prone to cysteine arylation in buffered aqueous solution ( $\mathrm{pH} 7.4)$ at $37^{\circ} \mathrm{C} .3^{37}$ Furthermore, compound 1 showed moderate antibacterial effects (MIC approx. $12.5-50 \mu \mathrm{M}$, unpublished data and ref. ${ }^{35}$ ) in a number of bacterial strains. The chemoselectivity with respect to cysteine arylation was assessed by reacting 1 with different model peptides. ${ }^{40}$ Interestingly, the compound was not able to promote other types of $C-X$ $(\mathrm{X}=\mathrm{N}$ or $\mathrm{O})$ cross-coupling reactions and did not arylate cysteines at the $\mathrm{N}$-terminal side. Based on the obtained results, a general reaction mechanism for cysteine arylation was proposed whereby a cysteinate residue first binds $\mathrm{Au}(\mathrm{III})$ trans to the $\mathrm{N}$ of the $\mathrm{C}^{\wedge} \mathrm{N}$ ligand via a ligand exchange reaction. Afterwards, a second amino acid residue or backbone nucleophile coordinates to $\mathrm{Au}(\mathrm{III})$, favouring the bond breakage between the nitrogen and the metal centre (Fig. 1b). ${ }^{41}$ Formation of the latter intermediate is crucial to promote the subsequent $\mathrm{C}-\mathrm{S}$ cross-coupling via reductive elimination. 
a

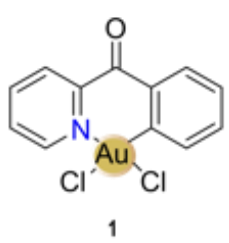

b
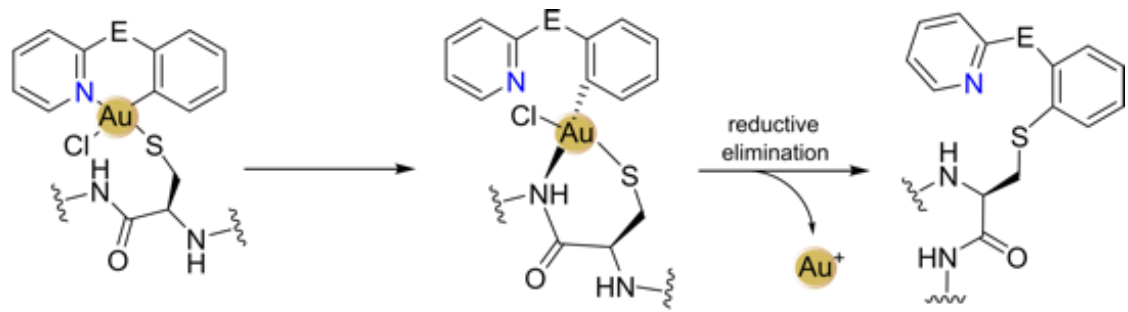

c
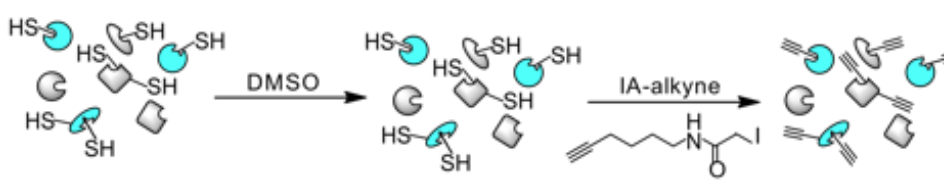

bacterial proteome
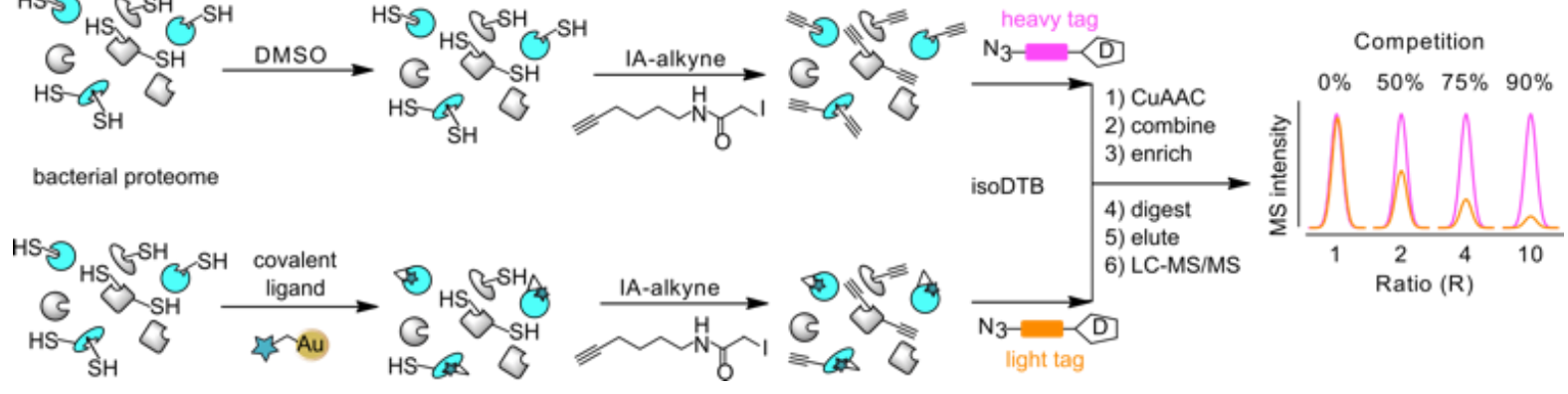

Figure 1. (a) Structure of the cyclometalated complex $\left[\mathrm{Au}\left(\mathrm{C}^{\mathrm{CO}} \mathrm{N}\right) \mathrm{Cl}_{2}\right]\left(\mathbf{1}, \mathrm{C}^{\mathrm{CO}} \mathrm{N}=2\right.$ benzoylpyridine). (b) Proposed mechanism of cysteine arylation templated by compound 1 via reductive elimination. (c) Workflow of isoDTB-ABPP experiments. isoDTB: isotopically labeled affinity tags, D: desthiobiotin.

Following these promising results, we envisaged the application of compounds of this family as i) tools for competitive residue-specific chemoproteomic technologies to enable profiling of unprecedented ligandable cysteine residues in bacterial cells, 8,9 and/or ii) as promising novel cysteine-targeted antibacterial agents. Therefore, we started investigating in an unbiased fashion, which cysteines can be engaged with this organogold compound class in the entire S. aureus proteome. To avoid laborious synthesis of $\mathrm{Au}(\mathrm{III}) \mathrm{C}^{\wedge} \mathrm{N}$ complexes with suitable affinity handles, we applied a competitive approach based on the isoDTB-ABPP technology (Fig 1c). ${ }^{7}$ In brief, in this strategy, the $S$. aureus proteome is split into two samples, one of which is treated with compound $\mathbf{1}$ and the other one with DMSO as a solvent control. In the next step, iodoacetamide alkyne (IA-alkyne $)^{8}$ is used to label many cysteine residues with alkynes. At the sites, at which compound $\mathbf{1}$ is already bound, this reactivity is blocked leading to a difference in alkyne modification between the inhibitor-treated and control-treated sample at these specific sites. This difference is read out using isotopically labelled (light and heavy) desthiobiotin azide (isoDTB) tags that are appended by cupper-catalyzed azide-alkyne cycloaddition (CUAAC) ${ }^{42}$ and after combination of the two samples used for enrichment. Following digestion of the enriched proteins, the modified peptides are eluted and analysed by liquid chromatography coupled to tandem mass spectrometry (LC-MS/MS).

Afterwards, the abundance of the alkynylated peptides can be relatively quantified between the two samples using the light and heavy isotopic label allowing quantification of the degree of binding of compound 1 . While cysteines that are not bound by 1 will show ratios between the heavy and light channel close to $R=1$, the specific targets of 1 will show high ratios $(R \gg>1)$. As the modified peptides are directly detected, this technology not only allows determination of the target proteins, but also of the exact interaction sites. In this way, a global understanding of the binding sites that are ligandable by compound $\mathbf{1}$ is obtained in the entire $S$. aureus proteome.

Following this chemoproteomic approach, S. aureus cell extracts were treated with compound $\mathbf{1}$ at room temperature for 1 hour at concentrations ranging from $10 \mu \mathrm{M}$ to $100 \mu \mathrm{M}$. It should be noted that $\mathbf{1}$ is only moderately active as antibacterial agent on S. aureus culture (MIC values $12.5-50$ $\mu \mathrm{M}) .{ }^{35}$ Therefore, we deprioritized the identification of targets in living cells at low concentrations and rather focused on the broad mapping of cysteines that are ligandable with this compound class in lysates at higher concentrations; thus, avoiding potential issues with compound's uptake.

Using the isoDTB-ABPP platform, we obtained data on a total of 1486 cysteines in the $S$. aureus proteome (Table S1). While at $100 \mu \mathrm{M}$ broad competition at many targets was observed (see Fig. S1), we detected a much narrower window of specifically competed proteins at $50 \mu \mathrm{M}$ and below (Fig. 2a,b and Fig. S1). For all further analysis, we therefore focussed on the proteins that were significantly engaged $\left(\log _{2}(R)>2, \mathrm{p}<0.05\right)$ at $50 \mu \mathrm{M}$ or below. In this way, we identified 108 cysteines that are ligandable by compound 1.

Interestingly, 27 of these cysteines were found in proteins encoded by essential genes ${ }^{43}$ and, of those, 10 were assigned to be close to the respective functional protein sites (Fig. 2C). ${ }^{44}$ The latter include catalytic nucleophiles (Cys-151 in gapA1, Cys-2 in glmS and Cys-102 of $\mathrm{mnmA}$ ), other active site residues (Cys-134 in trxB and Cys-112 in fabH), residues of metal binding sites (Cys-24 of rpsZ, Cys-100 of glmU, Cys-829 in secA1 and Cys-38 in tarJ) and residues of nucleotide binding sites (Cys-44 and Cys275 in metK). ${ }^{44}$ In line with what we observed for organic molecules as competitors, ${ }^{45}$ we detected concentrationdependent competition for many cysteines (Fig. 2d) that could be fit with a dose response model, indicating that the isoDTB-ABPP method gives quantitative, residuespecific engagement data also for organometallic compounds. Moreover, of the 108 cysteines liganded by compound 1, 59 were not liganded by any member of a 

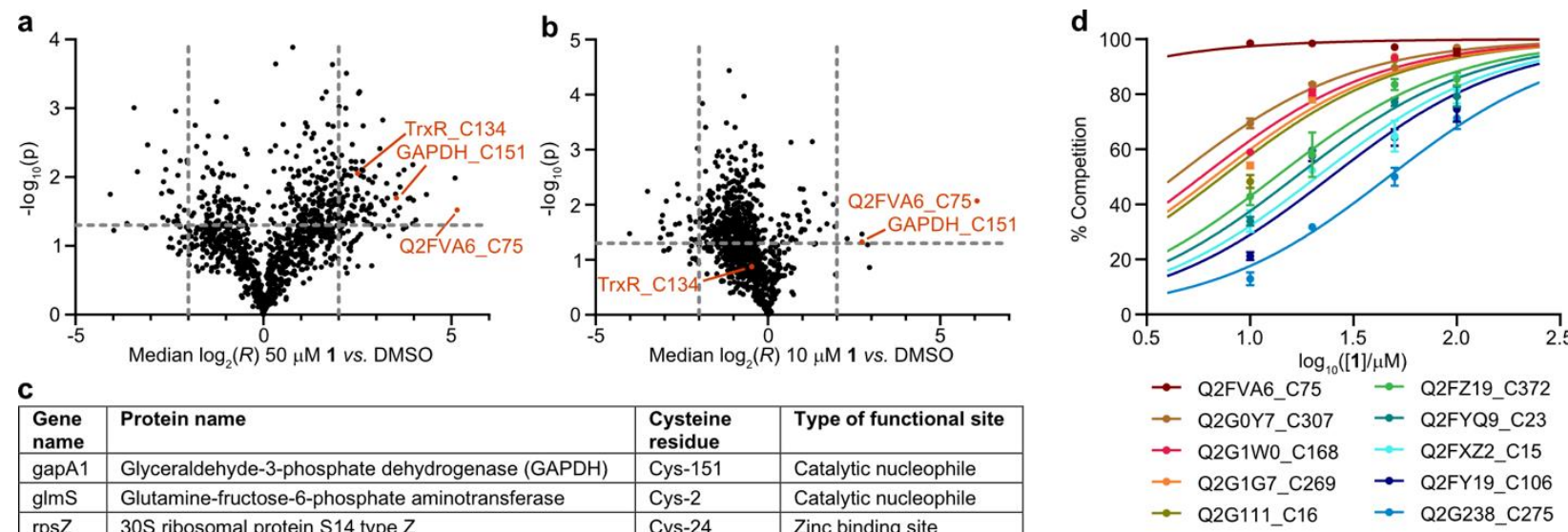

C
\begin{tabular}{|l|l|l|l|}
\hline $\begin{array}{l}\text { Gene } \\
\text { name }\end{array}$ & Protein name & $\begin{array}{l}\text { Cysteine } \\
\text { residue }\end{array}$ & Type of functional site \\
\hline gapA1 & Glyceraldehyde-3-phosphate dehydrogenase (GAPDH) & Cys-151 & Catalytic nucleophile \\
\hline glmS & Glutamine-fructose-6-phosphate aminotransferase & Cys-2 & Catalytic nucleophile \\
\hline rpsZ & 30 S ribosomal protein S14 type Z & Cys-24 & Zinc binding site \\
\hline $\mathrm{mnmA}$ & tRNA-specific 2-thiouridylase MnmA & Cys-102 & Catalytic nucleophile \\
\hline glmU & Bifunctional protein GImU & Cys-100 & Magnesium binding site \\
\hline metK & S-adenosylmethionine synthase & $\begin{array}{l}\text { Cys-44, } \\
\text { Cys-275 }\end{array}$ & $\begin{array}{l}\text { Potassium binging site, } \\
\text { ATP binding site }\end{array}$ \\
\hline secA1 & Protein translocase subunit SecA 1 & Cys-829 & Zinc binding site \\
\hline tarJ & Ribulose-5-phosphate reductase 1 & Cys-38 & Zinc binding site \\
\hline fabH & 3-oxoacyl-[acyl-carrier-protein] synthase 3 & Cys-112 & Active site \\
\hline trxB & Thioredoxin reductase (TrxR) & Cys-134 & Redox-active site \\
\hline
\end{tabular}

e

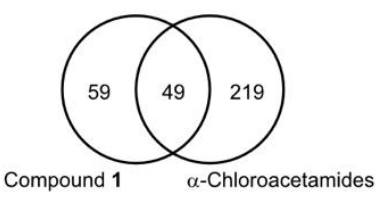

Figure 2. (a,b) Volcano plots of the isoDTB-ABPP experiments that show the median $\log _{2}(R)$ of the ratio between the heavy (compound-treated) and light (DMSO-treated) channels and the - $\log _{10}(\mathrm{p})$ of the statistical significance in a one-sample t-test for all quantified cysteines for compound 1 at $50 \mu \mathrm{M}$ (a) and $10 \mu \mathrm{M}$ (b). Grey dotted lines indicate the cut-offs of $\log _{2}(R)= \pm 2$ and $p<0.05$ that were used for hit selection. Selected proteins discussed in the text are highlighted in orange. (c) Cysteines liganded by 1 at $50 \mu \mathrm{M}$ or below that are in annotated functional sites of proteins encoded by essential genes. *: Functional site inferred from the $100 \%$ identical gene with Uniprot code P66011. (d) Concentration dependence of the degree of competition determined using isoDTB-ABPP for a selection of cysteines. Data points represent the median, error bars the standard deviation and lines a dose-response curve fit. All experiments were performed in duplicate. (e) Venn diagram of the ligandable cysteines identified in this study with compound 1 and in a previous study with a library of $\alpha$-chloroacetamides. ${ }^{7}$

previously screened $\alpha$-chloroacetamide library (Fig. 2e, Table S1). ${ }^{7}$ These unique targets include Cys-44 of metK, Cys-24 of rpsZ and Cys-829 in secA1, located in functional sites of proteins encoded by essential genes (Fig. 2c). These results indicate that organometallic compounds like 1 indeed access a different portion of the proteome and can, therefore, be very beneficial to target binding sites that are hard to address with organic compounds.

Of note, one of the competed cysteines was located in the functional site of the protein encoded by gapA1, corresponding to Glyceraldehyde-3-phosphate dehydrogenase (GADPH) an enzyme recently unveiled as a target of antibacterial $\mathrm{Ag}^{+}$ions in E. coli, and inhibited by $\mathrm{Cu}^{+}$in S. aureus. ${ }^{46,}{ }^{47}$ Moreover, the results highlighted Cys-134 of the bacterial thioredoxin reductase (TrxR, Fig. 2a,c) as one targeted residue. In bacteria, TrxR belongs to the antioxidant thioredoxin system ${ }^{48,49}$ and features a redox active site disulfide/dithiol couple consisting of Cys-134 and Cys-137. Interestingly, TrxR has already been proposed as pharmacological target for antibacterial goldbased compounds. ${ }^{50-53}$

To assess the relevance of compound $\mathbf{1}$ binding to cysteine residues with respect to enzyme activity, we conducted enzyme inhibition studies on the bacterial target TrxR using a DTNB-based plate reader assay (see Experimental for details). ${ }^{50}$ Thus, purified S. aureus TrxR was treated with $\mathbf{1}$ at different concentrations and incubated for $75 \mathrm{~min}$ at $25{ }^{\circ} \mathrm{C}$. In accordance with the isoDTB-ABPP data, compound 1 efficiently inhibits the TrxR activity $\left(I C_{50}=0.258 \pm 0.052 \mu \mathrm{M}\right.$, Fig. S2).

As competition of IA-alkyne labelling in isoDTB-ABPP experiments, as well as TrxR inhibition, is in principle possible by either coordination of the $\mathrm{Au}(\mathrm{III})$ centre to the target cysteine or by the aforementioned C-S cross- coupling arylation reaction, we set out to validate the actual mechanisms-of-action on one of our identified target proteins, namely the GCN5-like putative $\mathrm{N}$-acetyltransferase (Uniprot code Q2FVA6). While this protein is not encoded by an essential gene, it stood out by its high engagement even at $10 \mu \mathrm{M}$ of compound 1 ( $R=67$ at $10 \mu \mathrm{M}$ corresponding to $>98 \%$ competition). At this concentration, 1 showed high selectivity for competition of Cys-75 of this protein (Fig. 2b) having only four other targets with significantly lower $R$ values. It should be noted that Cys-75 is not competed by any $\alpha$ chloroacetamide in our earlier study (Table S1), ${ }^{7}$ although it was quantified for all of these compounds, showing that this is an interaction that is specific to the gold complex $\mathbf{1}$. Additionally, in a published NMR structure, ${ }^{54}$ Cys-75 is close to the thioester of the cofactor acetyl CoA ( $3.3 \AA$, Fig. 3a) indicating that blocking it with compound $\mathbf{1}$ has the potential to inhibit the enzyme activity.

The relatively small size of this protein (approx. $11.9 \mathrm{kDa}$ ) allowed us to perform intact protein highresolution electro-spray ionization mass spectrometry studies (HR-ESI-MS) following previously reported procedures. ${ }^{37,} 55,56$ In detail, the wild type GCN5-like putative $\mathrm{N}$-acetyltransferase (WT) and its mutant (Mu, C75A) were incubated at a concentration of $5 \mu \mathrm{M}$ with compound 1 in 1:3 ratio in $\mathrm{H}_{2} \mathrm{O} / \mathrm{ACN}(2: 1)$ for 1 hour at room temperature. Figure 3 shows the mass spectra for the wild-type protein before and after treatment with 1 . The obtained results demonstrate the formation of the $\mathrm{Au}(\mathrm{III})$ coordination adduct [WT-Met+Au"'I(CCON) $]^{\mathrm{n}}$ obtained upon exchange of the two chlorido ligands of $\mathbf{1}$, as well as the cysteine arylation product [WTMet+(CCON) $]^{\text {n+ }}$ (Fig. 3, Table S2-S3). These results are in line with previously reported reactivity studies of 

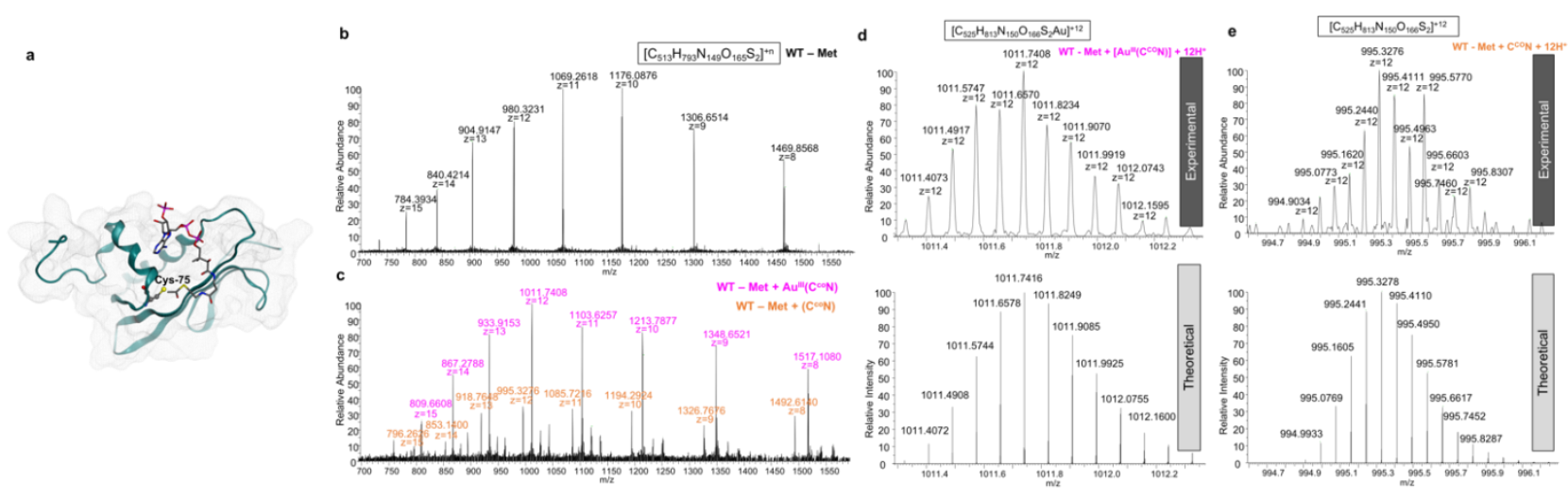

Figure 3. (a) Structure of the GCN5-like putative $\mathrm{N}$-acetyltransferase (PDB: $2 \mathrm{H} 5 \mathrm{M}$ ). The ligandable Cys-75 is highlighted. The cofactor acetyl CoA is shown as sticks. (b,c) Reference spectra of WT GCN5-like putative N-acetyltransferase before (b) and after (c) addition of $\left[\mathrm{Au}^{\prime \prime \prime}\left(\mathrm{C}^{\mathrm{CO}} \mathrm{N}\right) \mathrm{Cl}_{2}\right]$ incubated for $1 \mathrm{~h}$ at room temperature. (d,e) Comparisons

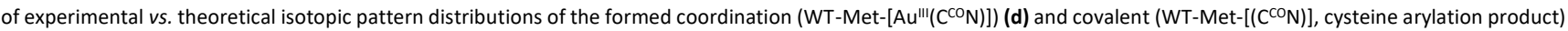
(e) adducts.

compound 1 and derivatives with model peptides. ${ }^{36,37,40}$ Of note, the unbound WT protein species could not be identified in the gold-treated sample indicating the protein's marked reactivity with compound $\mathbf{1}$. Interestingly, in the case of the C75A mutant, only formation of species featuring a bound gold fragment of general formula [Mu-Met+Au $\left.{ }^{\prime \prime \prime}\left(C^{C O} N\right)\right]^{\mathrm{n}+}$ were identified, while the signals of the unbound protein were still detected (Fig. S3, Table S2-S3). As expected, the cysteine arylation product could not be detected in this experiment.

Overall, inhibition of the enzymatic activity of TrxR as well as arylation of Cys-75 of GCN5-like putative $\mathrm{N}$-acetyltransferase validate the data that we obtained in the isoDTB-ABPP study and verify that arylation with compound 1 can proceed on unprecedented proteins identified using this technology. Thus, our data delivers a map of ligandable cysteines in $S$. aureus that can be addressed with organogold compounds such as $\mathbf{1}$, which might constitute the basis for a new family of antibacterials acting as covalent binders of cysteine residues.

\section{Conclusions}

Transition-metal-based strategies to selectively modify proteins hold promise in addressing challenges in chemical biology and in the development of novel therapeutic approaches for different diseases. Here, we have successfully profiled cysteines in the pathogenic bacterium $S$. aureus that can be liganded with the organogold compound 1 using the isoDTB-ABPP technology. In this way, more than 100 cysteines that are liganded by this compound were identified, of which more than 50 could not be liganded by any member of a previously investigated library of cysteine-directed $\alpha$ chloroacetamides.

Notably, we identified 10 ligandable cysteines in functional sites of proteins encoded by essential genes, which include proteins relevant to metal and redox homeostasis in bacteria and which are prime candidates to be explored further for potential pharmacological relevance. Further target validation studies showed potent inhibition of bacterial TrxR by compound 1 in vitro. In addition, the GCN5-like putative $\mathrm{N}$-acetyltransferase, that stood out through very high engagement by compound 1 in the isoDTB-ABPP studies, was shown to undergo cysteine arylation by $\mathbf{1}$, whereas the $\mathrm{C} 75 \mathrm{~A}$ mutant is not subjected to this covalent modification. Therefore, these results demonstrate the high cysteine selectivity of the arylation reaction templated by the $A u(I I I)$ complex and further validate the isoDTB-ABPP technology for cysteine profiling in complex bacterial lysates.

Overall, our study shows that $\mathrm{Au}(\mathrm{III})$ cyclometalated compounds have a high potential to address unique binding sites in the proteome, where they can promote selective metal-templated bioorthogonal reactions and thereby elicit biological effects that are not attainable with organic molecules in a straightforward fashion. Despite these promising results in bacterial lysates, compound $\mathbf{1}$ shows only moderate antibacterial activity against S. aureus. This could be due to different factors, including its extracellular deactivation caused by competitive binding to extracellular components, low uptake into bacterial cells or by an insufficiently high engagement of the relevant cysteines in the complex cell environment. Therefore, further optimization of the compound's scaffold to improve the antibacterial activity will be necessary in the future, for example including targeting functionalities in the $\mathrm{C}^{\wedge} N$ backbone. ${ }^{38,57}$ It is worth mentioning that, in a recent study, some of us reported on a cyclometalated $\mathrm{Au}(\mathrm{III}) \mathrm{C}^{\wedge} \mathrm{N}$ analogue of $\mathbf{1}$ with promising antibacterial effects, that is now undergoing target engagement studies at relevant concentrations in living bacteria. ${ }^{35}$

In summary, we demonstrate for the first time that residue-specific chemoproteomic experiments with the isoDTB-ABPP platform allow the competitive profiling of the targets of organometallic compounds in the complex environment of the cellular lysate. As many metal complexes that could potentially bind to or react selectively with cysteine residues have been reported to have antibacterial activity, ${ }^{10,} 20$ this study opens up the field of quantitatively studying their cellular interactions using residue-specific chemoproteomics, provided that 
the bonding interactions will be sufficiently stable. Through performance of such experiments in bacteria to identify relevant targets, as well as in human cell lines to identify potential off-targets, we envision that this technology will make significant contributions to realising the potential of metal complexes as antibacterial drugs in the near future.

\section{Conflicts of interest}

There are no conflicts to declare.

\section{Acknowledgements}

S.M.H. acknowledges funding by the Fonds der Chemischen Industrie through a Liebig Fellowship and by the TUM Junior Fellow Fund. C.S. thanks the Dr. Ing. Leonhard Lorenz-Stiftung for their financial support. M.Z. gratefully acknowledges funding by the Studienstiftung des Deutschen Volkes through a Ph.D. fellowship and by the Marianne-Plehn-Programm. We gratefully acknowledge Prof. Stephan A. Sieber and his group for their generous support. Dr. Darren Wragg is gratefully acknowledged for designing Figure $3 a$.

\section{References}

1 Murray, C. J. L.; Ikuta, K. S.; Sharara, F.; Swetschinski, L.; Robles Aguilar, G.; Gray, A.; Han, C.; Bisignano, C.; Rao, P.; Wool, E.; Johnson, S. C.; Browne, A. J.; Chipeta, M. G.; Fell, F.; Hackett, S.; Haines-Woodhouse, G.; Kashef Hamadani, B. H.; Kumaran, E. A. P.; McManigal, B.; Agarwal, R.; Akech, S.; Albertson, S.; Amuasi, J.; Andrews, J.; Aravkin, A.; Ashley, E.; Bailey, F.; Baker, S.; Basnyat, B.; Bekker, A.; Bender, R.; Bethou, A.; Bielicki, J.; Boonkasidecha, S.; Bukosia, J.; Carvalheiro, C.; CastañedaOrjuela, C.; Chansamouth, V.; Chaurasia, S.; Chiurchiù, S.; Chowdhury, F.; Cook, A. J.; Cooper, B.; Cressey, T. R.; Criollo-Mora, E.; Cunningham, M.; Darboe, S.; Day, N. P. J.; De Luca, M.; Dokova, K.; Dramowski, A.; Dunachie, S. J.; Eckmanns, T.; Eibach, D.; Emami, A.; Feasey, N.; FisherPearson, N.; Forrest, K.; Garrett, D.; Gastmeier, P.; Giref, A. Z.; Greer, R. C.; Gupta, V.; Haller, S.; Haselbeck, A.; Hay, S. I.; Holm, M.; Hopkins, S.; Iregbu, K. C.; Jacobs, J.; Jarovsky, D.; Javanmardi, F.; Khorana, M.; Kissoon, N.; Kobeissi, E.; Kostyanev, T.; Krapp, F.; Krumkamp, R.; Kumar, A.; Kyu, H. H.; Lim, C.; Limmathurotsakul, D.; Loftus, M. J.; Lunn, M.; Ma, J.; Mturi, N.; Munera-Huertas, T.; Musicha, P.; Mussi-Pinhata, M. M.; Nakamura, T.; Nanavati, R.; Nangia, S.; Newton, P.; Ngoun, C.; Novotney, A.; Nwakanma, D.; Obiero, C. W.; Olivas-Martinez, A.; Olliaro, P.; Ooko, E.; Ortiz-Brizuela, E.; Peleg, A. Y.; Perrone, C.; Plakkal, N.; Ponce-de-Leon, A.; Raad, M.; Ramdin, T.; Riddell, A.; Roberts, T.; Robotham, J. V.; Roca, A.; Rudd, K. E.; Russell, N.; Schnall, J.; Scott, J. A. G.; Shivamallappa, M.; Sifuentes-Osornio, J.; Steenkeste, N.; Stewardson, A. J.; Stoeva, T.; Tasak, N.; Thaiprakong, A.; Thwaites, G.; Turner, C.; Turner, P.; van Doorn, H. R.; Velaphi, S.; Vongpradith, A.; Vu, H.; Walsh, T.; Waner, S.; Wangrangsimakul, T.; Wozniak, T.; Zheng, P.; Sartorius, B.; Lopez, A. D.; Stergachis, A.; Moore, C.; Dolecek, C.; Naghavi, M., Global burden of bacterial antimicrobial resistance in 2019: a systematic analysis. The Lancet 2022, 399 (10325), 629-655.

2 Lakemeyer, M.; Zhao, W.; Mandl, F. A.; Hammann, P.; Sieber, S. A., Thinking Outside the Box-Novel Antibacterials To Tackle the Resistance Crisis. Angewandte Chemie International Edition 2018, 57 (44), 1444014475.

3 Martin, J. K., II; Sheehan, J. P.; Bratton, B. P.; Moore, G. M.; Mateus, A.; Li, S. H.-J.; Kim, H.; Rabinowitz, J. D.; Typas, A.; Savitski, M. M.; Wilson, M. Z.; Gitai, Z., A Dual-Mechanism Antibiotic Kills Gram-Negative Bacteria and Avoids Drug Resistance. Cell 2020, 181 (7), 1518-1532.e14.

4 Le, P.; Kunold, E.; Macsics, R.; Rox, K.; Jennings, M. C.; Ugur, I.; Reinecke, M.; Chaves-Moreno, D.; Hackl, M. W.; Fetzer, C.; Mandl, F.
A. M.; Lehmann, J.; Korotkov, V. S.; Hacker, S. M.; Kuster, B.; Antes, I.; Pieper, D. H.; Rohde, M.; Wuest, W. M.; Medina, E.; Sieber, S. A., Repurposing human kinase inhibitors to create an antibiotic active against drug-resistant Staphylococcus aureus, persisters and biofilms. Nature Chemistry 2020, 12 (2), 145-158.

5 Stokes, J. M.; Yang, K.; Swanson, K.; Jin, W.; Cubillos-Ruiz, A.; Donghia, N. M.; MacNair, C. R.; French, S.; Carfrae, L. A.; Bloom-Ackermann, Z.; Tran, V. M.; Chiappino-Pepe, A.; Badran, A. H.; Andrews, I. W.; Chory, E. J.; Church, G. M.; Brown, E. D.; Jaakkola, T. S.; Barzilay, R.; Collins, J. J., A Deep Learning Approach to Antibiotic Discovery. Cell 2020, 180 (4), 688-702.e13.

6 Imai, Y.; Meyer, K. J.; linishi, A.; Favre-Godal, Q.; Green, R.; Manuse, S.; Caboni, M.; Mori, M.; Niles, S.; Ghiglieri, M.; Honrao, C.; Ma, X.; Guo, J. J.; Makriyannis, A.; Linares-Otoya, L.; Böhringer, N.; Wuisan, Z. G.; Kaur, H.; Wu, R.; Mateus, A.; Typas, A.; Savitski, M. M.; Espinoza, J. L.; O’Rourke, A.; Nelson, K. E.; Hiller, S.; Noinaj, N.; Schäberle, T. F.; D'Onofrio, A.; Lewis, K., A new antibiotic selectively kills Gram-negative pathogens. Nature 2019, 576 (7787), 459-464.

7 Zanon, P. R. A.; Lewald, L.; Hacker, S. M., Isotopically Labeled Desthiobiotin Azide (isoDTB) Tags Enable Global Profiling of the Bacterial Cysteinome. Angewandte Chemie International Edition 2020, 59 (7), 2829-2836.

8 Weerapana, E.; Wang, C.; Simon, G. M.; Richter, F.; Khare, S.; Dillon, M. B. D.; Bachovchin, D. A.; Mowen, K.; Baker, D.; Cravatt, B. F., Quantitative reactivity profiling predicts functional cysteines in proteomes. Nature 2010, 468 (7325), 790-795.

9 Backus, K. M.; Correia, B. E.; Lum, K. M.; Forli, S.; Horning, B. D.; González-Páez, G. E.; Chatterjee, S.; Lanning, B. R.; Teijaro, J. R.; Olson, A. J.; Wolan, D. W.; Cravatt, B. F., Proteome-wide covalent ligand discovery in native biological systems. Nature 2016, 534 (7608), 570-574.

10 Frei, A.; Zuegg, J.; Elliott, A. G.; Baker, M.; Braese, S.; Brown, C.; Chen, F.; G. Dowson, C.; Dujardin, G.; Jung, N.; King, A. P.; Mansour, A. M.; Massi, M.; Moat, J.; Mohamed, H. A.; Renfrew, A. K.; Rutledge, P. J.; Sadler, P. J.; Todd, M. H.; Willans, C. E.; Wilson, J. J.; Cooper, M. A.; Blaskovich, M. A. T., Metal complexes as a promising source for new antibiotics. Chemical Science 2020, 11 (10), 2627-2639.

11 Griffith, D. M.; Li, H.; Werrett, M. V.; Andrews, P. C.; Sun, H., Medicinal chemistry and biomedical applications of bismuth-based compounds and nanoparticles. Chemical Society Reviews 2021, 50 (21), 1203712069.

12 Glišić, B. Đ.; Djuran, M. I., Gold complexes as antimicrobial agents: an overview of different biological activities in relation to the oxidation state of the gold ion and the ligand structure. Dalton Transactions 2014, 43 (16), 5950-5969

13 Harbut, M. B.; Vilchèze, C.; Luo, X.; Hensler, M. E.; Guo, H.; Yang, B.; Chatterjee, A. K.; Nizet, V.; Jacobs, W. R., Jr.; Schultz, P. G.; Wang, F., Auranofin exerts broad-spectrum bactericidal activities by targeting thiol-redox homeostasis. Proc Natl Acad Sci U S A 2015, 112 (14), 44534458.

14 Vellé, A.; Maguire, R.; Kavanagh, K.; Sanz Miguel, P. J.; Montagner, D., Steroid-Aul-NHC Complexes: Synthesis and Antibacterial Activity. ChemMedChem 2017, 12 (11), 841-844.

15 Stenger-Smith, J. R.; Mascharak, P. K., Gold Drugs with $\left\{\mathrm{Au}\left(\mathrm{PPh}_{3}\right)\right\}^{+}$ Moiety: Advantages and Medicinal Applications. ChemMedChem 2020, 15 (22), 2136-2145

16 Wang, H.; Wang, M.; Xu, X.; Gao, P.; Xu, Z.; Zhang, Q.; Li, H.; Yan, A.; Kao, R. Y.-T.; Sun, H., Multi-target mode of action of silver against Staphylococcus aureus endows it with capability to combat antibiotic resistance. Nature Communications 2021, 12 (1), 3331.

17 Hess, J., Rational approaches towards inorganic and organometallic antibacterials. Biological Chemistry 2021, doi: 10.1515/hsz-2021-0253.

18 de Almeida, A.; Oliveira, B. L.; Correia, J. D. G.; Soveral, G.; Casini, A., Emerging protein targets for metal-based pharmaceutical agents: An update. Coordination Chemistry Reviews 2013, 257 (19), 2689-2704.

19 Casini, A.; Guerri, A.; Gabbiani, C.; Messori, L., Biophysical characterisation of adducts formed between anticancer metallodrugs and selected proteins: new insights from $\mathrm{X}$-ray diffraction and mass spectrometry studies. Journal of Inorganic Biochemistry 2008, 102 (5-6), 955-1006.

20 Rodríguez, J.; Martínez-Calvo, M., Transition-Metal-Mediated Modification of Biomolecules. Chemistry - A European Journal 2020, 26 (44), 9792-9813. 
21 van de L'Isle, M. O. N.; Ortega-Liebana, M. C.; Unciti-Broceta, A., Transition metal catalysts for the bioorthogonal synthesis of bioactive agents. Curr Opin Chem Biol 2021, 61, 32-42.

22 Chalker, J. M.; Wood, C. S. C.; Davis, B. G., A Convenient Catalyst for Aqueous and Protein Suzuki-Miyaura Cross-Coupling. Journal of the American Chemical Society 2009, 131 (45), 16346-16347.

23 Ma, X.; Wang, H.; Chen, W., N-Heterocyclic Carbene-Stabilized Palladium Complexes as Organometallic Catalysts for Bioorthogonal CrossCoupling Reactions. The Journal of Organic Chemistry 2014, 79 (18), 8652-8658.

24 Ruiz-Castillo, P.; Buchwald, S. L., Applications of Palladium-Catalyzed CN Cross-Coupling Reactions. Chemical Reviews 2016, 116 (19), 1256412649.

25 Link, A. J.; Tirrell, D. A., Cell Surface Labeling of Escherichia coli via Copper(1)-Catalyzed [3+2] Cycloaddition. Journal of the American Chemical Society 2003, 125 (37), 11164-11165.

26 Coverdale, J. P. C.; Romero-Canelón, I.; Sanchez-Cano, C.; Clarkson, G. J.; Habtemariam, A.; Wills, M.; Sadler, P. J., Asymmetric transfer hydrogenation by synthetic catalysts in cancer cells. Nature Chemistry 2018, 10 (3), 347-354.

27 Weng, C.; Shen, L.; Ang, W. H., Harnessing Endogenous Formate for Antibacterial Prodrug Activation by in cellulo Ruthenium-Mediated Transfer Hydrogenation Reaction. Angewandte Chemie International Edition 2020, 59 (24), 9314-9318.

28 Tsubokura, K.; Vong, K. K. H.; Pradipta, A. R.; Ogura, A.; Urano, S.; Tahara, T.; Nozaki, S.; Onoe, H.; Nakao, Y.; Sibgatullina, R.; Kurbangalieva, A.; Watanabe, Y.; Tanaka, K., In Vivo Gold Complex Catalysis within Live Mice. Angewandte Chemie International Edition 2017, 56 (13), 3579-3584.

29 Streu, C.; Meggers, E., Ruthenium-Induced Allylcarbamate Cleavage in Living Cells. Angewandte Chemie International Edition 2006, 45 (34), 5645-5648.

30 Bertrand, B.; Casini, A., A golden future in medicinal inorganic chemistry: the promise of anticancer gold organometallic compounds. Dalton Transactions 2014, 43 (11), 4209-4219.

31 Bertrand, B.; Spreckelmeyer, S.; Bodio, E.; Cocco, F.; Picquet, M.; Richard, P.; Le Gendre, P.; Orvig, C.; Cinellu, M. A.; Casini, A., Exploring the potential of gold(iii) cyclometallated compounds as cytotoxic agents: variations on the $C^{\wedge} N$ theme. Dalton Transactions 2015, 44 (26), 1191111918.

32 Spreckelmeyer, S.; van der Zee, M.; Bertrand, B.; Bodio, E.; Stürup, S.; Casini, A., Relevance of Copper and Organic Cation Transporters in the Activity and Transport Mechanisms of an Anticancer Cyclometallated Gold(III) Compound in Comparison to Cisplatin. Frontiers in Chemistry 2018, 6 (377).

33 Babak, M. V.; Chong, K. R.; Rapta, P.; Zannikou, M.; Tang, H. M.; Reichert, L.; Chang, M. R.; Kushnarev, V.; Heffeter, P.; Meier-Menches, S. M.; Lim, Z. C.; Yap, J. Y.; Casini, A.; Balyasnikova, I. V.; Ang, W. H., Interfering with Metabolic Profile of Triple-Negative Breast Cancers Using Rationally Designed Metformin Prodrugs. Angewandte Chemie International Edition 2021, 60 (24), 13405-13413.

34 Pintus, A.; Aragoni, M. C.; Cinellu, M. A.; Maiore, L.; Isaia, F.; Lippolis, V.; Orrù, G.; Tuveri, E.; Zucca, A.; Arca, M., [Au(pyb-H)(mnt)]: A novel gold(III) 1,2-dithiolene cyclometalated complex with antimicrobial activity (pyb- $\mathrm{H}=\mathrm{C}$-deprotonated 2-benzylpyridine; $\mathrm{mnt}=1,2$ dicyanoethene-1,2-dithiolate). Journal of Inorganic Biochemistry 2017, 170, 188-194.

35 Chakraborty, P.; Oosterhuis, D.; Bonsignore, R.; Casini, A.; Olinga, P.; Scheffers, D.-J., An Organogold Compound as Potential Antimicrobial Agent against Drug-Resistant Bacteria: Initial Mechanistic Insights. ChemMedChem 2021, 16 (19), 3060-3070.

36 Wenzel, M. N.; Meier-Menches, S. M.; Williams, T. L.; Rämisch, E.; Barone, G.; Casini, A., Selective targeting of PARP-1 zinc finger recognition domains with $\mathrm{Au}(\mathrm{iii})$ organometallics. Chemical Communications 2018, 54 (6), 611-614.

37 Wenzel, M. N.; Bonsignore, R.; Thomas, S. R.; Bourissou, D.; Barone, G.; Casini, A., Cyclometalated Aulll Complexes for Cysteine Arylation in Zinc Finger Protein Domains: towards Controlled Reductive Elimination. Chemistry - A European Journal 2019, 25 (32), 7628-7634.

38 Kung, K. K.-Y.; Ko, H.-M.; Cui, J.-F.; Chong, H.-C.; Leung, Y.-C.; Wong, M.K., Cyclometalated gold(iii) complexes for chemoselective cysteine modification via ligand controlled $\mathrm{C}-\mathrm{S}$ bond-forming reductive elimination. Chemical Communications 2014, 50 (80), 11899-11902.

39 de Paiva, R. E. F.; Du, Z.; Nakahata, D. H.; Lima, F. A.; Corbi, P. P.; Farrell, N. P., Gold-Catalyzed C-S Aryl-Group Transfer in Zinc Finger Proteins. Angewandte Chemie International Edition 2018, 57 (30), 9305-9309.

40 Thomas, S. R.; Bonsignore, R.; Sánchez Escudero, J.; Meier-Menches, S. M.; Brown, C. M.; Wolf, M. O.; Barone, G.; Luk, L. Y. P.; Casini, A., Exploring the Chemoselectivity towards Cysteine Arylation by Cyclometallated $\mathrm{Au}(\mathrm{III})$ Compounds: New Mechanistic Insights. Chembiochem 2020, 21 (21), 3071-3076

41 Thomas, S. R.; Casini, A., Gold compounds for catalysis and metalmediated transformations in biological systems. Current Opinion in Chemical Biology 2020, 55, 103-110.

42 Rostovtsev, V. V.; Green, L. G.; Fokin, V. V.; Sharpless, K. B., A Stepwise Huisgen Cycloaddition Process: Copper(I)-Catalyzed Regioselective "Ligation" of Azides and Terminal Alkynes. Angewandte Chemie International Edition 2002, 41 (14), 2596-2599.

43 Chaudhuri, R. R.; Allen, A. G.; Owen, P. J.; Shalom, G.; Stone, K.; Harrison, M.; Burgis, T. A.; Lockyer, M.; Garcia-Lara, J.; Foster, S. J.; Pleasance, S. J.; Peters, S. E.; Maskell, D. J.; Charles, I. G., Comprehensive identification of essential Staphylococcus aureus genes using Transposon-Mediated Differential Hybridisation (TMDH). BMC Genomics 2009, 10 (291)

44 TheUniProtConsortium, UniProt: the universal protein knowledgebase in 2021. Nucleic Acids Research 2021, 49 (D1), D480-D489.

45 Lee, K. M.; Le, P.; Sieber, S. A.; Hacker, S. M., Degrasyn exhibits antibiotic activity against multi-resistant Staphylococcus aureus by modifying several essential cysteines. Chemical Communications 2020, 56 (19), 2929-2932.

46 Wang, H.; Wang, M.; Yang, X.; Xu, X.; Hao, Q.; Yan, A.; Hu, M.; Lobinski, R.; Li, H.; Sun, H., Antimicrobial silver targets glyceraldehyde-3phosphate dehydrogenase in glycolysis of E. coli. Chemical Science 2019, 10 (30), 7193-7199.

47 Tarrant, E.; P Riboldi, G.; Mcllvin, M. R.; Stevenson, J.; BarwinskaSendra, A.; Stewart, L. J.; Saito, M. A.; Waldron, K. J., Copper stress in Staphylococcus aureus leads to adaptive changes in central carbon metabolism. Metallomics 2019, 11 (1), 183-200.

48 Williams Jr, C. H.; Arscott, L. D.; Müller, S.; Lennon, B. W.; Ludwig, M. L.; Wang, P.-F.; Veine, D. M.; Becker, K.; Schirmer, R. H., Thioredoxin reductase. European Journal of Biochemistry 2000, 267 (20), 6110-6117.

49 Arnér, E. S. J.; Holmgren, A., Physiological functions of thioredoxin and thioredoxin reductase. European Journal of Biochemistry 2000, 267 (20), 6102-6109.

50 Schmidt, C.; Karge, B.; Misgeld, R.; Prokop, A.; Franke, R.; Brönstrup, M.; Ott, I., Gold(I) NHC Complexes: Antiproliferative Activity, Cellular Uptake, Inhibition of Mammalian and Bacterial Thioredoxin Reductases, and Gram-Positive Directed Antibacterial Effects. Chemistry - A European Journal 2017, 23 (8), 1869-1880.

51 Schmidt, C.; Karge, B.; Misgeld, R.; Prokop, A.; Brönstrup, M.; Ott, I., Biscarbene gold(i) complexes: structure-activity-relationships regarding antibacterial effects, cytotoxicity, TrxR inhibition and cellular bioavailability. MedChem Comm 2017, 8 (8), 1681-1689.

52 Schmidt, C.; Albrecht, L.; Balasupramaniam, S.; Misgeld, R.; Karge, B.; Brönstrup, M.; Prokop, A.; Baumann, K.; Reichl, S.; Ott, I., A gold(i) biscarbene complex with improved activity as a $\operatorname{TrxR}$ inhibitor and cytotoxic drug: comparative studies with different gold metallodrugs. Metallomics 2019, 11 (3), 533-545.

53 53. Büssing, R.; Karge, B.; Lippmann, P.; Jones, P. G.; Brönstrup, M.; Ott, I., Gold(I) and Gold(III) N-Heterocyclic Carbene Complexes as Antibacterial Agents and Inhibitors of Bacterial Thioredoxin Reductase. ChemMedChem 2021, 16 (22), 3402-3409.

54 Cort, J. R.; Ramelot, T. A.; Murray, D.; Acton, T. B.; Ma, L.-C.; Xiao, R.; Montelione, G. T.; Kennedy, M. A., Structure of an acetyl-CoA binding protein from Staphylococcus aureus representing a novel subfamily of GCN5-related N-acetyltransferase-like proteins. Journal of Structural and Functional Genomics 2008, 9 (1), 7-20.

55 Meier, S. M.; Gerner, C.; Keppler, B. K.; Cinellu, M. A.; Casini, A., Mass Spectrometry Uncovers Molecular Reactivities of Coordination and Organometallic Gold(III) Drug Candidates in Competitive Experiments That Correlate with Their Biological Effects. Inorganic Chemistry 2016, 55 (9), 4248-4259. 
56 Wenzel, M.; Casini, A., Mass spectrometry as a powerful tool to study therapeutic metallodrugs speciation mechanisms: Current frontiers and perspectives. Coordination Chemistry Reviews 2017, 352, 432-460.

57 Gukathasan, S.; Parkin, S.; Black, E. P.; Awuah, S. G., Tuning Cyclometalated Gold(III) for Cysteine Arylation and Ligand-Directed Bioconjugation. Inorganic Chemistry 2021, 60 (19), 14582-14593. 